\title{
Endplate Fracture Associated with Intradiscal Dextrose Injection
}

\author{
Michael L. Whitworth, MD
}

Intradiscal injections have been used for many years in the treatment of chronic pain. These injections consisted of many substances providing variable pain relief from discogenic pain.

Following an intradiscal dextrose injection series, a physically active patient developed superior and inferior lumbar endplate fractures, producing a drastic increase in pain. The pathology of endplate fractures and their

Intradiscal therapies for degenerative disc disease with maintenance of disc height and for contained disc herniations have advanced rapidly in theory and in technology over the past five years. The introduction of percutaneous techniques such as intradiscal electrothermal annuloplasty (1), which targets annular tears; coblation nucleoplasty (2), which decompresses central nucleus pulposis of the disc with subsequent decrement in peripheral pressures; and percutaneous endoscopic discectomy/annuloplasty (3), which provides direct treatment of annular tears with a ultra high radiofrequency bipolar probe have brought about advances in the treatment of this common condition. However, in patients who have intervertebral disc space narrowing of over $50 \%$, these options may be less than optimal. Other therapies such as percutaneous intradiscal fusion with expandable holders have been described (4) in addition to several types of artificial disc or nuclear replacements. Each of these techniques is being investigated for efficacy and as alternatives to invasive fusion surgery. Many other therapies have been attempted over the years, including most recently intradiscal glucose injections. A published peer reviewed study suggested benefits for intradiscal dextrose injections for the treatment of internal disc

From Columbus Pain Physicians, Columbus, Indiana. Dr. Whitworth is medical director at the Columbus Pain Physicians. Address correspondence: Michael Whitworth, MD, Columbus Pain Physicians, 2400 East 17th Street, Columbus, IN 47201. E-mail: paindoc2000@yahoo.com contribution to chronic low back pain is subsequently reviewed. A discussion of various intradiscal agent injections is included. Also, the pathophysiology of the production of endplate fractures as related to intradiscal injections is discussed.

Keywords: Endplate fracture, intradiscal Dextrose, intradiscal injections

degeneration in a series of 425 injections in 85 patients (5). There were no reported complications in the series. However a patient who received the same treatment in our series developed an endplate fracture of both the superior and inferior endplates after three glucose injections.

\section{CASE REPORT}

A 53 year old female presented with chronic low back pain without any referral or radicular symptoms and without a history of trauma, fever, weakness, loss of bowel or bladder control, or cancer. Physical exam revealed midline low back tenderness as the only pertinent positive finding. Plain film $\mathrm{x}$-rays were negative for any significant pathology. Discography was subsequently performed utilizing Omnipaque radiocontrast. Disc space collapse at L5-S1 with complete provocation of low back pain, moderate internal disc derangement at L3-4 and L4-5 with multiple Grade III annular tears (modified Dallas scale) and moderate low back pain concordant reproduction was observed. Treatment options discussed included selective endoscopic annuloplasty, fusion, artificial disc implantation, coblation nucleoplasty, and intradiscal glucose injections. The patient elected to proceed with the intradiscal glucose injection. After the experimental nature of the injection series was made known to the patient, an intradiscal glucose injection series was performed in the L3-4, L4-5, and L5-S1 disc using 1.5$2 \mathrm{~mL}$ of injectate. The injection solution consisted of final concentrations of dextrose $25 \%$ and bupivicaine $0.25 \%$ delivered through a 22 gauge 6 inch Chiba needle into 
the middle of each disc under fluoroscopic guidance. She received 3 treatments at biweekly intervals. Intravenous cefazolin was given prior to each injection and the skin preparation was made with repeated iodinated solution application followed by an alcohol preparation and air drying.

The patient reported a gradual decrease in her low back pain over the treatment period, incorporated yoga stretching exercises and walking exercise following the first two treatments. However, within two days after the third treatment, she began to complain of severe midline low back pain that was constant, unremitting, and was far worse than the original pain. On query, there were no associated fevers, chills, loss of bowel or bladder control, or referral of the pain distally. The low back was extremely tender to percussion yet the ESR and WBC were normal. An MRI demonstrated edema at L4-5 which the radiologist interpreted as possible disciitis (Fig 1). A contrast enhanced MRI demonstrated a pattern inconsistent with disciitis, but with consistent with pre-existing marrow edema. Because of unrelenting pain, in spite of activity restrictions and medication management, a repeat discogram (Fig 2) was performed. This study revealed contrast entering the superior and inferior vertebral bodies
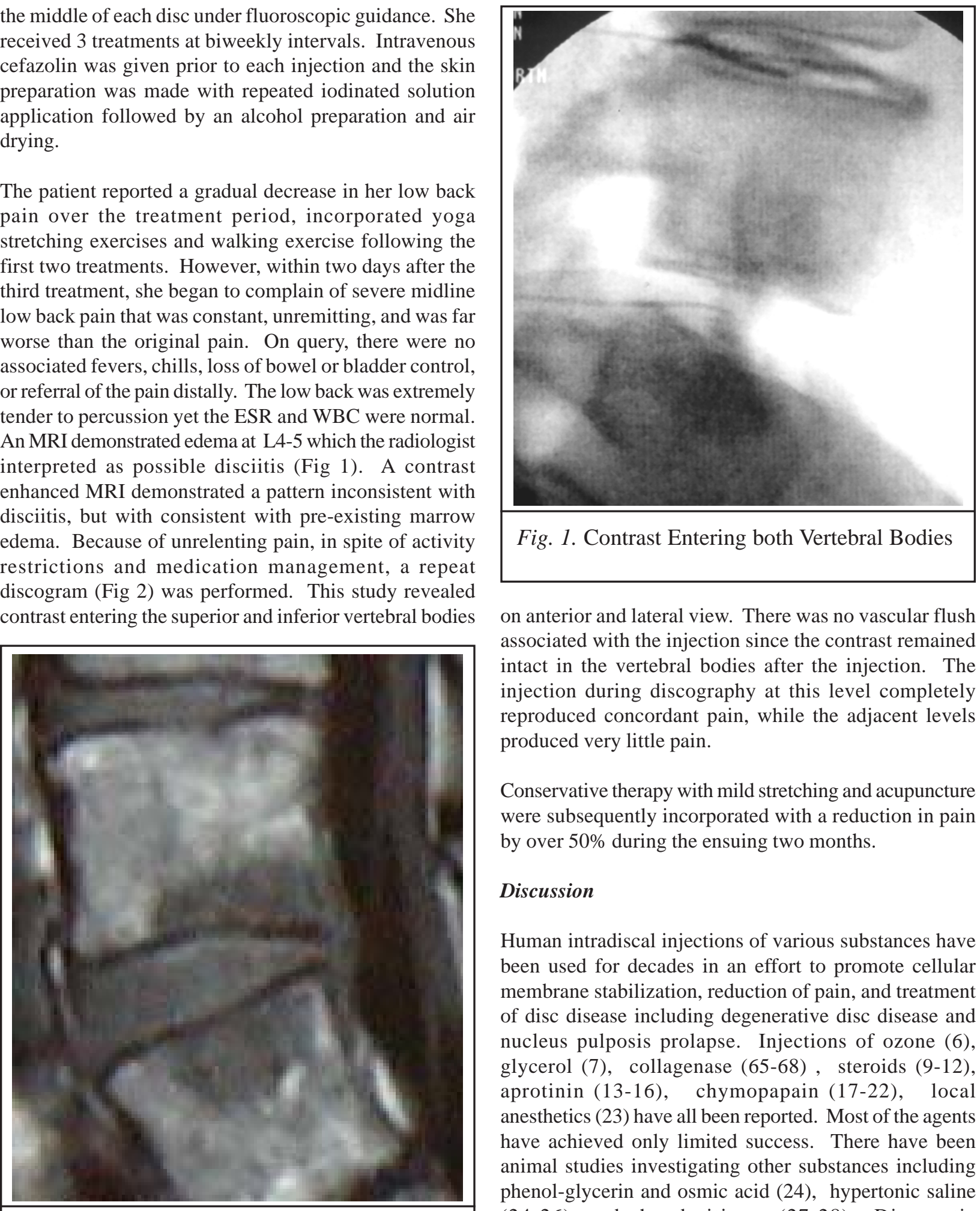

on anterior and lateral view. There was no vascular flush associated with the injection since the contrast remained intact in the vertebral bodies after the injection. The injection during discography at this level completely reproduced concordant pain, while the adjacent levels produced very little pain.

Conservative therapy with mild stretching and acupuncture were subsequently incorporated with a reduction in pain by over $50 \%$ during the ensuing two months.

\section{Discussion}

Human intradiscal injections of various substances have been used for decades in an effort to promote cellular membrane stabilization, reduction of pain, and treatment of disc disease including degenerative disc disease and nucleus pulposis prolapse. Injections of ozone (6), glycerol (7), collagenase (65-68), steroids (9-12), aprotinin (13-16), chymopapain (17-22), local anesthetics (23) have all been reported. Most of the agents have achieved only limited success. There have been animal studies investigating other substances including phenol-glycerin and osmic acid (24), hypertonic saline (24-26), and chondroitinase (27-28). Diagnostic intradiscal injections include the use of saline and iohexol Fig. 1. MRI Demonstrating Peri-endplate Edema for discography, and incorporation of intradiscal 
antibiotics as prophylaxis against bacterial disciitis.

Significant early onset complications from such injections have been rare, with the majority associated with chymopapain (29-33). Because the leakage rate from pressure injected discs approaches $14 \%$ (34), there is a realistic chance that any injection can contact the epidural space and nerve roots, thereby causing injury to these structures if the injectate is enzymatic as is chymopapain. Other early onset complications from intradiscal injections include up to a $4 \%$ incidence of convulsions and a $10 \%$ incidence of hypotension during discography according to one study (35). The same study showed the following day a $10 \%$ incidence of a severe headache and an $81 \%$ incidence of increased back pain. However, there are no other studies that corroborate this high incidence of side effects. There is one reference in the literature to a fatal pulmonary nucleus pulposivs embolism during discography (36).

Late onset complications from lumbar intradiscal injections can consist of disciitis, intradiscal calcification and granuloma following steroid injections, (37-40), chronic low back pain in certain subsets of patients without previous back pain (41), and late myelopathy after chymopapain injections (42). However, there are no longitudinal studies analyzing the long term consequences due to these injections. Animal histologic studies of the intervertebral disc after steroid injections reveals significant pathological changes in the disc (43).

The injection of a seemingly innocuous substance, dextrose, into the disc may be associated with less obvious consequences. The hyperosmolar nature of high concentrations of dextrose may in effect, cause imbibition (the absorption of a fluid, as the taking up of water by a gel) of the nucleus pulposis, with subsequent increases in intradiscal pressure. Studies of hypertonic saline injections in rats produced decreased intradiscal pressures over 112 weeks following injection (44-45), but the pressures within the first two days were not measured. The potential increase in intradiscal pressures from both the volume of injection, and the potential osmotic effect of swelling may create increased pressure on the endplates. Various truncal positions and vertebral body rotation can enhance the compressive and sheer forces imparted to the intervertebral disc. During exercise, intradiscal pressures may increase 2-3 fold (46-48). Also, it has been shown that endplate deflection of $0.3 \mathrm{~mm}$ is seen during discography pressurization in cadavers, which suggests the endplate may be a source of pain (8), and may result in significant endplate displacement.

While microfracture of the endplates, or a frank compression fracture are common in patients with osteoporosis (49), endplate disruption may be more common than is generally appreciated in degenerative disc disease (50). One study demonstrated a $6 \%$ incidence of overt fractures when patients demonstrated concordant pain reproduction during discography (51). These fractures were assumed to be pre-existing and there are few reports of iatrogenic causation. During pressurization of the nucleus, the vertical stresses are converted to horizontal stresses whose energy is absorbed by the annulus fibrosis. The endplate is deformed at a rate greater than that of the disc. Several studies have found axial loading of the spine to the point of failure causes disruption to the endplate rather than damage to the annulus fibrosus (52-56). Rolander and Blair (57) demonstrated the formation of a central stellate fissure in the endplate with load not exceeding that for fracture. In cases where fracture loads were exceeded, there were gross transverse or sagittal fractures with nuclear material entering into the vertebral body.

The limits of detection of microfractures of the endplates may be below those of clinical science at this time. It has been demonstrated that Modic endplate changes correlate poorly to lumbar discography findings (58), but this may be due to multiple pathologies (endplate microfractures and annular tears) being present simultaneously, thereby confounding discography results. Of concern is the presence of even minor endplate fractures can potentially cause a degenerative cascade. It has also been hypothesized that unrecognized endplate fractures are a major cause of chronic low back pain (59). Once endplate fractures occur, there is a reduced capability of load handling and energy absorbing capacities at the affected disc segment (60). The endplate is the weakest part of the vertebral segment and is the first part of the segment to develop fractures with repetitive loading (61). The type of endplate fracture has been correlated to the degree of disc degeneration, with central endplate fractures being more commonly seen with moderately degenerative discs while acute Schmorl's node fractures are associated with normal discs. (62). Once severe degenerative disc disease occurs, there is both a vascular and neuronal ingrowth associated with the endplates. The presence of endplate defects and increased sensory nerve in growth as demonstrated by increased calcitonin gene-related peptide (CGRP) and substance P immunoreactivity in the area of 
the endplate strongly suggests one of the major sources of pain in the degenerative disc is the endplate (63). Unfortunately the evidence for endplate fractures in degenerative disc disease is limited in the clinical setting due to the lack of sufficiently sensitive imaging methods. Although discography, magnetic resonance imaging, Computed Tomography (CT), and bone scans occasionally demonstrate endplate disruption, the occurrence in these diagnostic methods is rather low considering the relatively high incidence of degenerative disc disease. While it is probable the endplate fractures are of significant importance, it should be realized that not all endplate disruption is a cause for long term pain as evidenced by the lack of such after Holmium YAG laser endplate damage as seen on MRI (64) .

\section{CONCLUSION}

Intradiscal injections of hyperosmolar solutions have the potential to contribute to endplate fractures of the intervertebral discs. The intervertebral endplates with their potential for fractures, may be an underestimated cause of chronic low back pain, and may contribute to the cascade of degenerative disc disease.

\section{REFERENCES}

1. Saal JA, Saal JS. Intradiscal electrothermal treatment for chronic discogenic low back pain: prospective outcome study with a minimum 2-year follow-up. Spine 2002; 27:966-974.

2. Sharps, L, Isaac, Z. Percutaneous Disc Decompression Using Nucleoplasty. Pain Physician 2002; 5:121-126.

3. Marks RA. Transcutaneous lumbar diskectomy for internal disk derangement: a new indication. South Med J 2000; 93:885-890.

4. Gepstein. Percutaneous Intervertebral Fusion with Mechanical Disc Space Holders. Procedings of International $20^{\text {th }}$ Course for Percutaneous Endoscopic Spine. Surgery and Complementary Techniques, Zurich 2002.

5. Matthews R, Miller M, Bree S. Treatment of mechanical and chemical lumbar discopathy by dextrose 25\%. J Minim Invasive Spinal Tech 2001; 1:58-61.

6. D’Erme M, Scarchilli A, Artale AM et al. Ozone therapy in lumbar sciatic pain. Radiol Med. 1998; 95:21-24.

7. Kotilainen E, Muittari P, Kirvela O. Intradiscal glycerol or bupivacaine in the treatment of low back pain. Acta Neurochir (Wien). 1997; 139:541-545.

8. Heggeness MH, Doherty BJ. Discography causes endplate deflection. Spine 1993; 18:1050-1053.

9. Simmons JW, McMillin JN, Emery SF et al. Intradiscal steroids. A prospective double-blind clinical trial. Spine. 1992; S172-175.

10. Beltran Fabregat J. The intradiscal injection of triamcinolone hexacetonide: from alternative to abandonment. Med Clin (Barc). 1992; 99:38.

11. Bertin P, Rochet N, Arnaud M et al. Intradiscal injection of triamcinolone hexacetonide for acute, subacute, and chronic sciatica. Results at 3 months an open-prospectus study of 30 cases and review of the literature. Clin Rheumatol. 1990; 3:362-6.

12. Feffer HL. Therapeutic intradiscal hydrocortisone. A long-term study. Clin Orthop. 1969; 67:100-104

13. Vaquero J, Martinez R, Saucedo G. Intradiscal aprotinin in lumbar disk bulging. Surg Neurol. 1989; 31:245.

14. Lesoin F, Viaud C, Di Paola F et al. Treatment of soft cervical hernia by percutaneous intradiscal injection of aprotinin. Neurochirurgie. 1986; 32:272-275.

15. Lesoin F, Jomin M, Viaud C et al. Soft cervical disk protrusion. Use of percutaneous intradiscal aprotinin. Presse Med. 1984; 13:888.

16. Kraemer J, Laturnus H. Lumbar intradiscal instillation with aprotinin. Spine 1982; 7:73-74.

17. Steffen R, von Bremen-Kuhne R. Chemonucleolysis. Development, experiences, prospects. Orthopade 1999; 28:609-614.

18. Bradbury N, Wilson LF, Mulholland RC. Adolescent disc protrusions. A long-term follow-up of surgery compared to chymopapain. Spine 1996; 21:372-377.

19. Melrose J, Taylor TK, Ghosh P et al. Intervertebral disc reconstitution after chemonucleolysis with chymopapain is dependent on dosage. Spine 1996; 21:9-17.

20. Jerosch J, Castro WH, Halm $\mathrm{H}$ et al. Long-term changes in proton spin tomography following chemonucleolysis. Z Orthop Ihre Grenzgeb 1994; 132:2-8.

21. Gogan WJ, Fraser RD. Chymopapain. A 10-year, double-blind study. Spine 1992; 17:388-394.

22. Nachemson AL, Rydevik B. Chemonucleolysis for sciatica. A critical review. Acta Orthop Scand 1988; 59:56-62.

23. Milette PC, Fontaine S, Lepanto L et al. Radiating pain to the lower extremities caused by Lumbar disc disruption. AJNR 1996; 17:1195-1197.

24. Shioda M. Intradiscal injection of hypertonic saline, phenol-glycerin and osmic acid for the treatment of lumbar disc herniation: an experimental study. Nippon Seikeigeka Gakkai Zasshi 1995; 69:964-976.

25. Sato K, Nagata K, Hirohashi T. Intradiscal pressure after repeat intradiscal injection of hypertonic saline: an experimental study. Eur Spine J 2002; 11:52-56.

26. Sato K, Nagata K, Ariyoshi M et al. Intradiscal pressure after intradiscal injection of hypertonic saline: 
an experimental study. Eur Spine J 2000; 9:213-217.

27. Sasaki M, Takahashi T, Miyahara K et al. Effects of chondroitinase ABC on intradiscal pressure in sheep: an in vivo study. Spine 2001; 26:463-468.

28. Eurell JA, Brown MD, Ramos M. The effects of chondroitinase $\mathrm{ABC}$ on the rabbit intervertebral disc. A roentgenographic and histologic study. Clin Orthop. 1990; 256:238-243.

29. Eggen PJ, ter Bruggen JP, Wein BB et al. Aseptic spondylodiscitis: a complication of chemonucleolysis? A case report. Spine 1993; 18:2358-2361.

30. Pinkowski JL, Leeson MC. Anaphylactic shock associated with chymopapain skin test. A case report and review of the literature. Clin Orthop 1990; 260:186-190.

31. Grammer LC, Ricketti AJ, Schafer MF et al. Chymopapain allergy: case reports and identification of patients at risk for chymopapain anaphylaxis. Clin Orthop 1984; 188:139-143.

32. Agre K, Wilson RR, Brim M et al. Chymodiactin postmarketing surveillance. Demographic and adverse experience data in 29,075 patients. Spine 1984; 9:479485.

33. Jacobs DM, Lipton MH, Russell SM. Anaphylactic reactions following intradiscal injection of chymopapain under local anesthesia. J Bone Joint Surg (Am) 1984; 66:806-807.

34. MacMillan J, Schaffer JL, Kambin P. Routes and incidence of communication of lumbar discs with surrounding neural structures. Spine 1991; 16:167171.

35. Tallroth K, Soini J, Antti-Poika I et al. Premedication and short term complications in iohexol discography. Ann Chir Gynaecol 1991; 80:49-53.

36. Schreck RI, Manion WL, Kambin P et al. Nucleus pulposus pulmonary embolism. A case report. Spine 1995; 20:2463-2466.

37. Benmansour A, Filali K, Tijari A et al. Acquired lumbar block vertebra. Was intradiscal injection of triamcinolone hexacetonide a contributing factor? Rev Rhum Engl Ed 1999; 66:61-62.

38. Menkes CJ, Vallee C, Giraudet-Le Quintetret. Calcification of the epidural space following an intradiscal injection of triamcinolone hexacetonide. Presse Med; 1989; 18:1707.

39. Ito S, Usui H, Maruyama K et al. Roentgenographic evaluation of ossification and calcification of the lumbar spinal canal after intradiscal betamethasone injection. J Spinal Disord 2001; 14:434-438.

40. Menei P, Fournier D, Alhayek G et al. Calcificated necrotic inflammatory granuloma after intradiscal injection of triamcinolone hexacetonide. Rev Rhum Mal Osteoartic 1991; 58:605-609.

41. Carragee EJ, Chen Y, Tanner CM et al. Can discography cause long-term back symptoms in previously asymptomatic subjects? Spine 2000; 25:1803-1808.
42. Haag P, Munkel K, Meinck HM. Neurologische Universitatsklinik, Heidelberg. Late myelopathy after chemonucleolysis. Case report and review of the literature. Nervenarzt 1999; 70:920-923.

43. Aoki M, Kato F, Mimatsu K et al. Histologic changes in the intervertebral disc after intradiscal injections of methylprednisolone acetate in rabbits. Spine 1997; 22:127-131.

44. Sato K, Nagata K, Hirohashi T. Intradiscal pressure after repeat intradiscal injection of hypertonic saline: an experimental study. Eur Spine $J$ 2002; 11:52-56.

45. Sato K, Nagata K, Ariyoshi M et al. Intradiscal pressure after intradiscal injection of hypertonic saline: an experimental study. Eur Spine J 2000; 9:213-217.

46. Sato K, Kikuchi S, Yonezawa T. In vivo intradiscal pressure measurement in healthy individuals and in patients with ongoing back problems. Spine 1999; 24:2468-2474.

47. Steffen T, Baramki HG, Rubin R et al. Lumbar intradiscal pressure measured in the anterior and posterolateral annular regions during asymmetrical loading. Clin Biomech 1998; 13:495-505.

48. Wilke H, Neef P, Hinz B et al. Intradiscal pressure together with anthropometric data - a data set for the validation of models. Clin Biomech 2001; S111-126.

49. Antonacci MD, Mody DR, Rutz K et al. A histologic study of fractured human vertebral bodies. J Spinal Disord Tech 2002; 15:118-126.

50. Brown MF, Hukkanen MV, McCarthy ID et al. Sensory and sympathetic innervation of the vertebral endplate in patients with degenerative disc disease. $J$ Bone Joint Surg (Br) 1997; 79:147-153.

51. Adams MA, Freeman BJ, Morrison HP et al. Mechanical initiation of intervertebral disc degeneration. Spine 2000; 25:1625-1636.

52. Brown T, Hansen RJ, Yorra AJ: Some mechanical tests on the lumbosacral spine with particular reference to the intervertebral discs. J Bone Joint Surg 1957; 39A:1135.

53. Jayson MIV, Herbert CM, Barks, JS: Intervertebral discs: nuclear morphology and bursting pressures. Ann Rheum Dis 1973; 32:308-315.

54. Roaf R: A study of the mechanics of spinal injuries. $J$ Bone Joint Surg 1960; 428:810-812.

55. Smith FP: Experimental biomechanics of intervertebral disc rupture through vertebral body. J Neurosurg 1969; 30:134-139.

56. Virgin WJ: Experimental investigations into the physical properties of the intervertebral disc. $J$ Bone Joint Surg 1951; 33B:607-612.

57. Rolander SF, Blair WE: Deformation and fracture of the lumbar vertebral endplate. Orthop Clin North Am 1975; 6:75-81.

58. Sandhu HS, Sanchez-Caso LP, Parvataneni HK et al. Association between findings of provocative discography and vertebral endplate signal changes as 
seen on MRI. J Spinal Disord 2000; 13:438-443.

59. van Dieen JH, Weinans H, Toussaint HM. Fractures of the lumbar vertebral endplate in the etiology of low back pain: a hypothesis on the causative role of spinal compression in aspecific low back pain. Med Hypotheses 1999; 53:246-252.

60. Yoganandan N, Larson SJ, Pintar FA et al. Intravertebral pressure changes caused by spinal microtrauma. Neurosurgery 1994; 35:415-421.

61. Hansson T, Keller T, Jonson R. Fatigue fracture morphology in human lumbar motion segments. $J$ Spinal Disord 1988; 1:33-8122.

62. Hansson TH, Keller TS, Spengler DM. Mechanical behavior of the human lumbar spine. II. Fatigue strength during dynamic compressive loading. $J$ Orthop Res 1987; 5:479-487.

63. Brown MF, Hukkanen MV, McCarthy ID. Sensory and sympathetic innervation of the vertebral endplate in patients with degenerative disc disease. J Bone Joint Surg (Br) 1997; 79:147-153.
64. R. Princenthal, Eberich H, Clofford T et al. Vertebral endplate changes following thermodisckoplasty. $J$ Min Inv Spine Tech 2001; 1:44-45.

65. Wittenberg RH, Oppel S, Rubenthaler FA et al. Fiveyear results from chemonucleolysis with chymopapain or collagenase: a prospective randomized study. Spine 2001; 26:1835-1841.

66. Hedtmann A, Steffen R, Kramer J. Prospective comparative study of intradiscal high-dose and lowdose collagenase versus chymopapain. Spine 1987; 12:388-392.

67. Wintermantel E, Emde H, Loew F. Intradiscal collagenase for treatment of lumbar disc herniations. A comparison of clinical results and computed tomography follow-up. Acta Neurochir 1985; 78:98104.

68. Brown MD, Tompkins JS. Chemonucleolysis (discolysis) with collagenase. Spine 1986; 11:123130 . 